\title{
High Power LPP-EUV Source with Long Collector Mirror Lifetime for Semiconductor High Volume Manufacturing
}

\author{
Hakaru Mizoguchi*, Hiroaki Nakarai, Tamotsu Abe, Hiroshi Tanaka, \\ Yukio Watanabe, Tsukasa Hori, Takeshi Kodama, Yutaka Shiraishi, \\ Tatsuya Yanagida, Georg Soumagne, Tsuyoshi Yamada, and Takashi Saitou
}

Gigaphoton Inc. Hiratsuka facility, 3-25-1 Shinomiya, Hiratsuka, Kanagawa 254-8567, Japan

*hakaru_mizoguchi@gigaphoton.com

\begin{abstract}
We have developed Pilot \#1 system for HVM EUV lithography. Pilot\#1 is up running and it demonstrates HVM capability. We achieved following performances at present; High conversion efficiency $4.5 \%$ is realized with Pre-pulse technology. High speed $(>90 \mathrm{~m} / \mathrm{s}) \&$ small (20 micron) droplet is realized. High power $\mathrm{CO}_{2}$ laser power level is $20 \mathrm{~kW}$. Output power $250 \mathrm{~W}$ in-burst power @ $50 \%$ duty (125 W average) several min. Pilot\#1 system achieved potential of $89 \%$ availability ( 2 weeks) at $125 \mathrm{~W}$ average power. $-0.6 \% /$ Gpls with $125 \mathrm{~W}$ average was demonstrated during $30 \mathrm{Mpls}$ with mirror test.

Furthermore, in 2018 ASML reported they succeeded $250 \mathrm{~W}$ operation with NXE3350 system achieved 125 WPH throughput not only in laboratory but also several customer site. Corresponding this situation, we have redefined the new target of EUV source power more than $330 \mathrm{~W}$ recently. We have already started feasibility study of higher conversion efficiency, higher driver laser power and improvement of capping layer of collector mirror. We will report the preliminary result of these.
\end{abstract}

Keywords: Laser produced plasma, EUV, 13.5 nm, Lithography, Conversion efficiency, Pre-pulse laser, $\mathrm{CO}_{2}$ laser, Collector mirror

\section{Introduction}

Extreme ultraviolet (EUV) light source has been being developed together with a scanning exposure tool. As the tool with $10 \mathrm{~W}$ EUV light source, ASML shipped " $\alpha$-demo tool" in 2007 [1] and Nikon shipped EUV-1 in 2008 [2]. ASML has been developing $\beta$-tool; NXE-3100 in the beginning of 2011 with 100 W EUV light source $[3,4]$. Requirement of the EUV exposure tool is now in the $\beta$-tool; NXE3300 (for high volume manufacturing (HVM)) [5]. The required EUV power is $250 \mathrm{~W}$ clean power (after purifying infrared (IR) and deep ultra violet (DUV) spectra) at intermediate focus (IF). However still demonstrated power level was around $80 \mathrm{~W}[6,7]$ in 2013.

We have been developing $\mathrm{CO}_{2}$-Sn-LPP EUV light source which is the most promising solution as the $13.5 \mathrm{~nm}$ high power light source for HVM
EUVL. Unique and original technologies such as; combination of pulsed $\mathrm{CO}_{2}$ laser and $\mathrm{Sn}$ droplets, dual wavelength laser pulses shooting and mitigation with magnetic field have been developed in Gigaphoton Inc. We have developed first practical source for HVM; "GL200E" [8] in 2014. We have proved high average power $\mathrm{CO}_{2}$ laser more than $20 \mathrm{~kW}$ at output power cooperate with Mitsubishi electric cooperation [9]. Pilot\#1 demonstrated HVM capability; EUV power recorded at $111 \mathrm{~W}$ average $(117 \mathrm{~W}$ in burst stabilized, $95 \%$ duty) with $5 \%$ conversion efficiency for 22hours operation in October 2016 [10]. Recently we have demonstrated actual collector mirror reflectivity degradation rate is less than $-0.6 \% / \mathrm{Gp}$ by using real collector mirror around $125 \mathrm{~W}$ (at I/F clean) in burst power more than 10 Billion pulses operation. In this paper we introduce latest EUV source $125 \mathrm{~W}$ level EUV

\begin{tabular}{llr}
\hline Received & May & 9,2019 \\
Accepted & May & 24,2019
\end{tabular}


power demonstration by Pilot \#1 system.

Furthermore, in 2018 ASML reported they succeeded $250 \mathrm{~W}$ operation with NXE3350 system achieved 125 WPH throughput not only in laboratory but also several customer site [11]. Corresponding this situation, we have redefined the new target of EUV source power more than $330 \mathrm{~W}$ recently. We have already started feasibility study of higher conversion efficiency, higher driver laser power and improvement of capping layer of collector mirror. We will report the preliminary result of these.

\section{LPP EUV light source system and key components}

\subsection{System concept}

Since 2002, we have been developing the carbon dioxide $\left(\mathrm{CO}_{2}\right)$ laser produced Tin (Sn) plasma (CO2-Sn-LPP) EUV light source which is the most promising solution as the $13.5 \mathrm{~nm}$ high power $(>200 \mathrm{~W})$ light source for HVM EUV lithography (EUVL) We have chosen the LPP-EUV method because of its high efficiency, power scalability, and spatial freedom around plasma. Our group has proposed several unique original technologies $[12,13]$. The theoretical [14] and experimental [15] data have clearly demonstrated that combination of $\mathrm{CO}_{2}$ laser and $\mathrm{Sn}$ plasma realize high conversion efficiency (CE) from driver. The conceptual Structure of Gigaphoton HVM EUV light source is shown in Fig. 1. At first step Sn droplet target is irradiated with pre-pulse laser. The Sn droplet is crushed to sub-micron mists. The mists are expanded in time. At second step after certain delay time the mists cloud is expanded and heated by pulsed $\mathrm{CO}_{2}$ laser beam. The cloud is converted to high temperature plasma. Sn ions have several numbers of charges. During recombination process Sn plasma emits $13.5 \mathrm{~nm}$ EUV light. Most of the Sn ions can be trapped by the magnetic field by Larmor movement. To prevent the collector mirror from being contaminated, Sn plasma needs to be trapped before being deposited on the collector mirror. Residues of the plasma after emitting EUV light are eventually scattered inside the vessel. To enhance EUV energy and to maximize Sn debris mitigation, number of $\mathrm{Sn}$ ions should be maximized in these laser heating processes.

Our Sn debris mitigation concept with the magnetic field is simple. Because EUV light is emitted from the $\mathrm{Sn}$ plasma, which is mainly composed of Sn ions and electron, almost all the $\mathrm{Sn}$ ions can be trapped in the strong magnetic field.
Also, some neutral atoms can be guided and trapped by charge exchange with ions. In reality, however, not all the Sn atoms and ions can be trapped in the magnetic field [13]. We have investigated behaviors under various conditions to optimize Sn debris mitigation parameters in the compact EUV generation tool (patented).

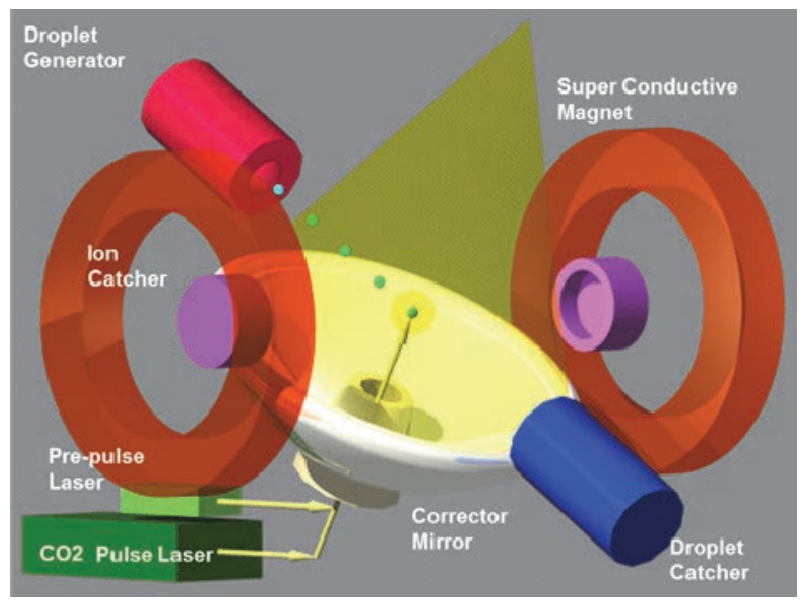

Fig. 1. The concept of Gigaphoton HVM EUV light source.

\subsection{Pre-pulse technology $[13,16]$}

CE of $4.7 \%$ with the $20 \mu \mathrm{m}$ in diameter droplet has been demonstrated by optimizing the pre-pulse laser conditions as shown in Fig. 2 (red dot) with small experimental device. These basic studies have contributed to the development of the high-power production machine and to the basic design for further EUV power scaling together with theoretical calculations. These phenomena are explainable with difference of pre-pulse expansion mechanism of ns-pulse and ps-pulse. This high CE technology enables $250 \mathrm{~W}$ EUV source with 20 $\mathrm{kW} \mathrm{CO}$ laser.

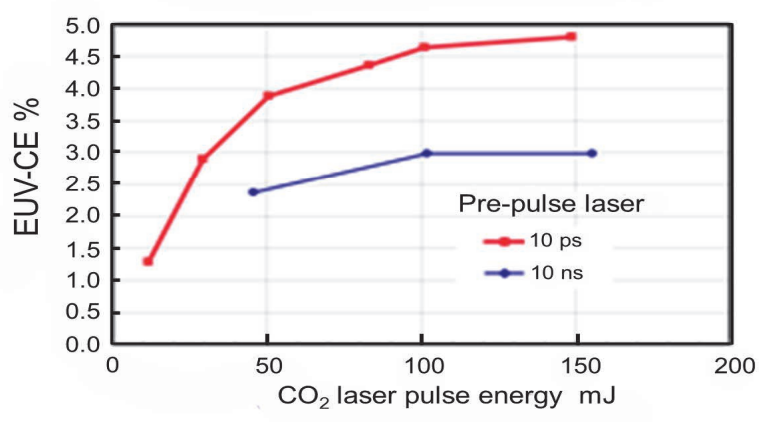

Fig. 2. Conversion efficiency vs. $\mathrm{CO}_{2}$ laser energy. 
The amount and the distribution of the Sn neutral atoms after the pre-pulse laser irradiation in a certain magnetic field were observed with the Laser Induced Fluorescence (LIF) method. On the other hand, in case of 10 ps pre-pulse ionization rate is very high even in case of low $\mathrm{CO}_{2}$ pulse energy (Fig. 3).

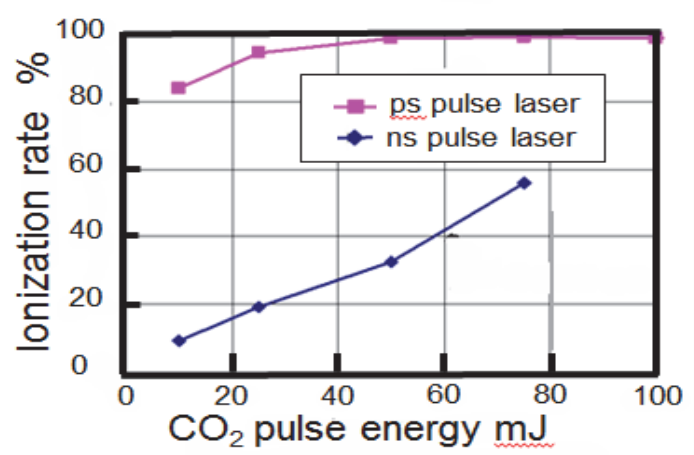

Fig. 3. Ionization ratio vs. $\mathrm{CO}_{2}$ laser energy.

\subsection{Driver laser system development}

We have developed system technology and component test at proto \#1 since 2011 [17-19]. The new $\mathrm{CO}_{2}$ laser amplifier has been developed by co-operate with Mitsubishi electric supported by NEDO [20]. We have started the construction of proto \#2 system in $2 \mathrm{H}$ of 2013. In 2015 we succeeded to demonstrate $20 \mathrm{~kW}$ output power with combination of pre-amplifier by Mitsubishi electric, and other $\mathrm{CO}_{2}$ laser by the Trump at proto \#2 test bench (Fig. 4) [21]. The operation has started beginning of 2014 (Fig. 5).

This system achieved $20 \mathrm{~kW}$ with $15 \mathrm{~ns}$ pulse duration, repetition rate was $100 \mathrm{kHz}$. We have demonstrated $256 \mathrm{~W}$ EUV emission in burst operation with $95 \%$ duty cycle by proto $\# 2$ device [19].

In 2016 we developed $27 \mathrm{~kW} \mathrm{CO} 2$ driver laser system for Pilot \#1 system. (15ns pulse duration, repetition rate was $100 \mathrm{kHz}$ ) composed with one pre-amplifier and three main amplifier produced by Mitsubishi electric. Also outlook of the whole driver laser system is shown in Fig. 5. The beam profile is much better than Proto $\# 2 \mathrm{CO}_{2}$ driver laser system [21]. Difference of Driver $\mathrm{CO}_{2}$ laser beam profile of Proto \#2 system and Pilot \#1 is shown in Fig. 6. Beam profile of Pilot \#1 system is much symmetrical and homogeneous. This
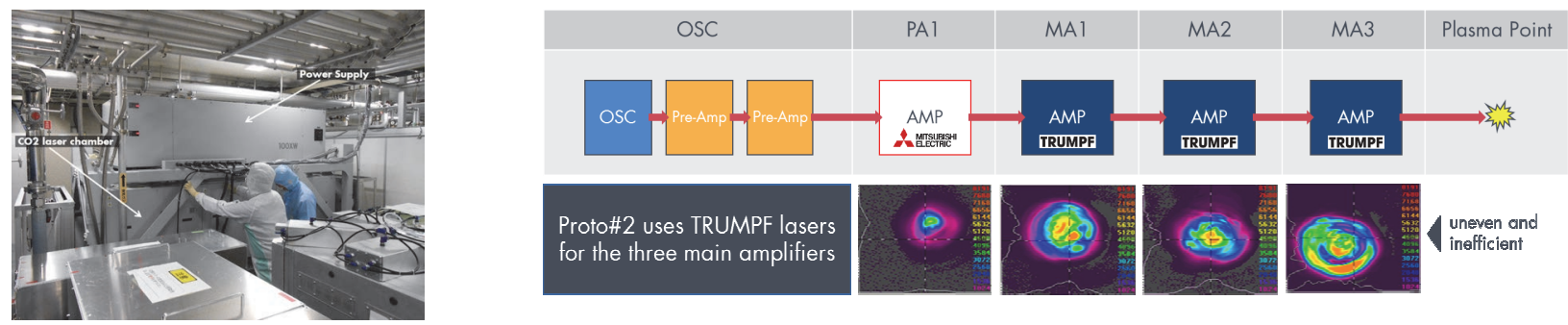

Fig. 4. $\mathrm{CO}_{2}$ laser pre-amplifier installation by Mitsubishi electric.
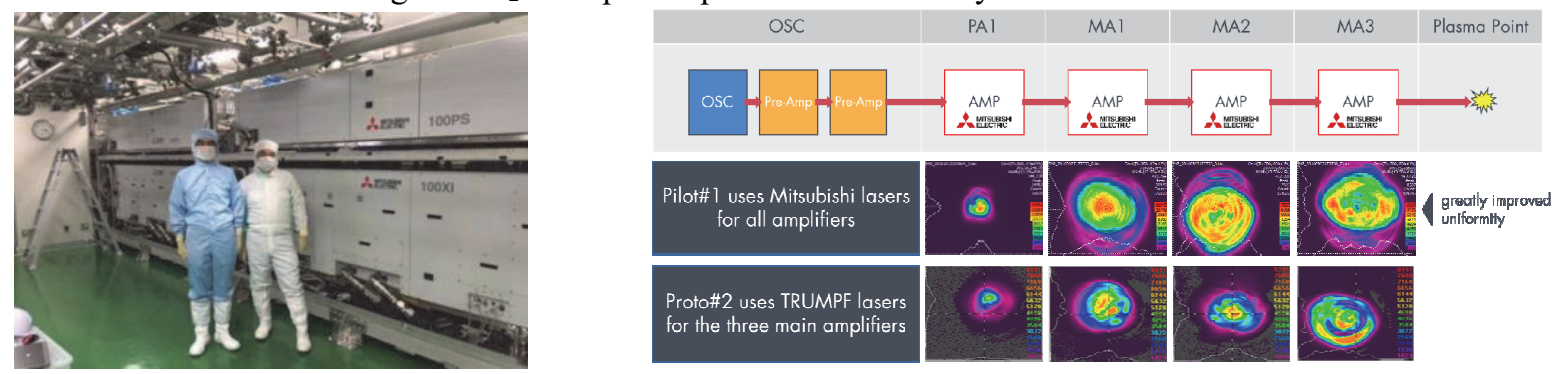

Fig. 5. Pre-amplifier $+3 \times$ main amplifier installation by Mitsubishi Electric.
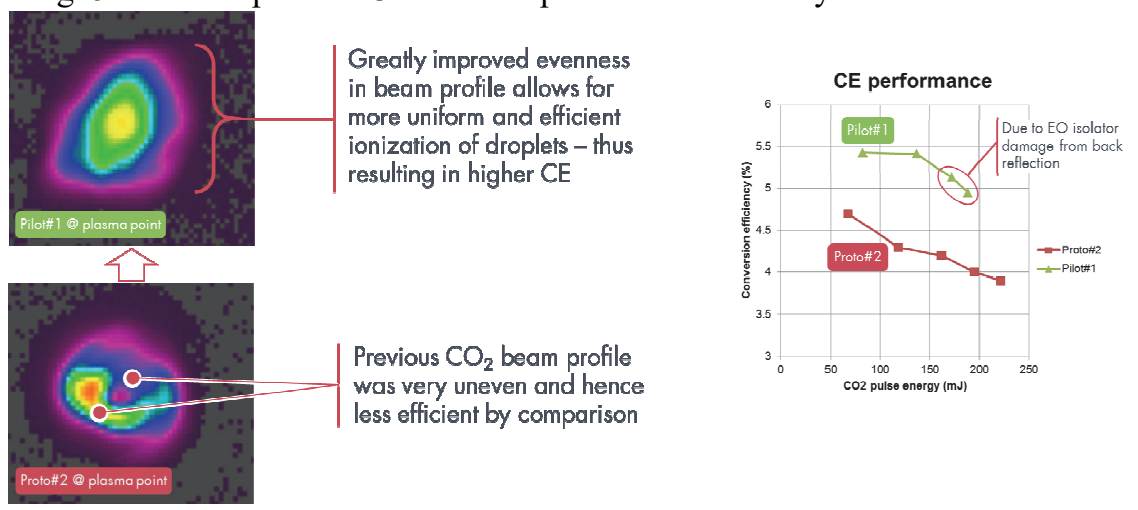

Fig. 6. Driver laser beam profile and conversion efficiency. 
difference makes difference of conversion efficiency. Pilot \#1 system achieved significant progress of conversion efficiency between 5.0\% and $5.5 \%$. We expect this homogeneity coming from difference of excitation scheme of $\mathrm{CO}_{2}$ laser [22].

\section{Latest operation data of Pilot\#1 system}

3.1. Operation data of EUV emission

Since 2016, we started the operation of Pilot \#1 system (Fig. 7). One example of the operation data of the Pilot \#1 system is shown in Table 1. Also EUV emission data and dose stability data is shown in Fig. 8 and Fig. 9. This tata shows very good stability. The measured data shows $96.9 \%$ die yield [10].

\subsection{Mitigation data of collector mirror}

Picture of actual collector mirror is shown in Fig. 10. Diameter is around $400 \mathrm{~mm}$, weight is $22 \mathrm{~kg}$. Collector reflectivity is $>48 \%$. The shape of the mirror is ellipsoid and one focal point is plasma

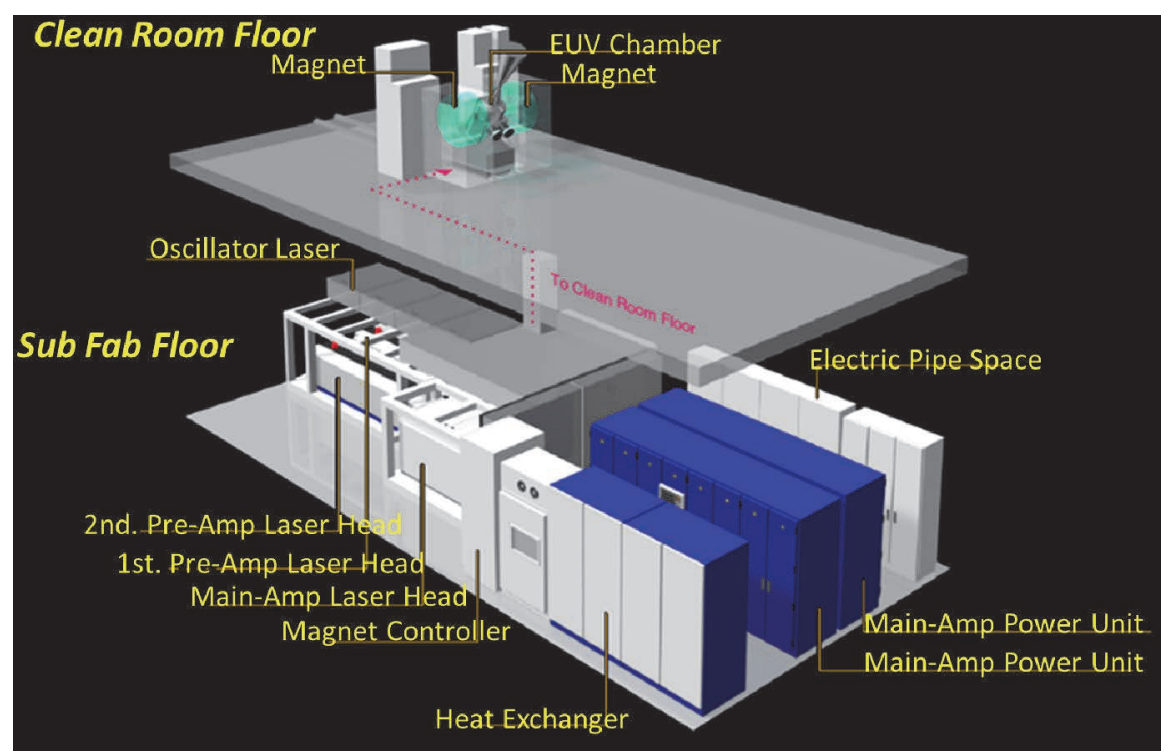

Fig. 7. GL200E-Pilot\#1.

Table 1. Summary of operational data.

\begin{tabular}{lc} 
& Performance \\
\hline Average power at IF & $125 W$ \\
\hline Dose error (3 sigma) ${ }^{*} 1$ & $0.09 \%$ \\
\hline Die yield $(<0.16 \%)^{*} 2$ & $96.9 \%$ \\
\hline Operation time & $28 \mathrm{~h}$ \\
\hline Pulse Number & $108 \mathrm{pls}$ \\
\hline Duly cycle & $100 \%$ \\
\hline In-band power & $125 \mathrm{~W}$ \\
\hline Dose margin & $30 \%$ \\
\hline Collector lifetime *3 & -- \\
\hline Repetition rate & $100 \mathrm{kHz}$ \\
\hline Note & \\
*1: Dose orror is dofined by 800 pulse (8 ms) moving window \\
*2 Dose performance failure is mainly due to dropletcombination failure \\
*3: Dummy mirror was used for invostigation.
\end{tabular}



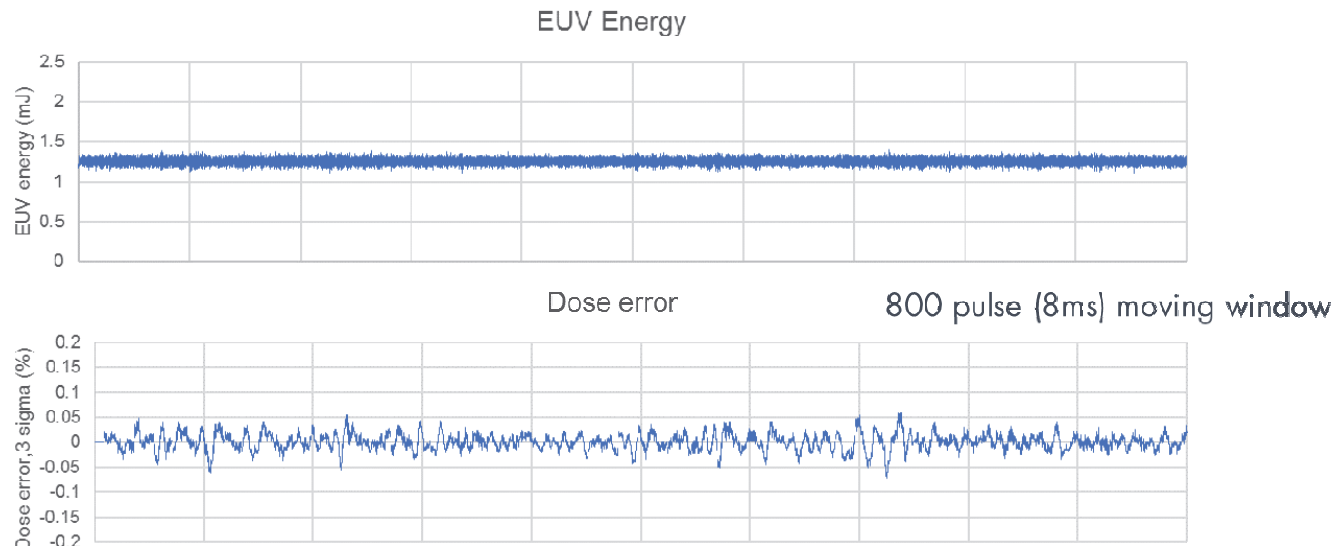

CO2 Energy

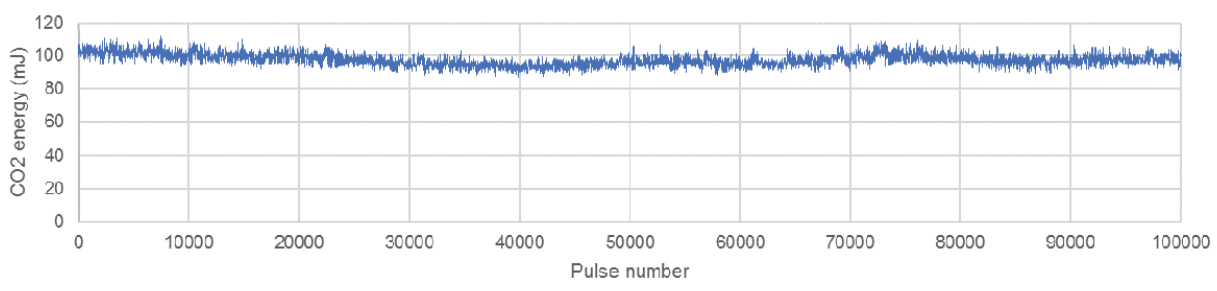

Fig. 8. EUV emission data.
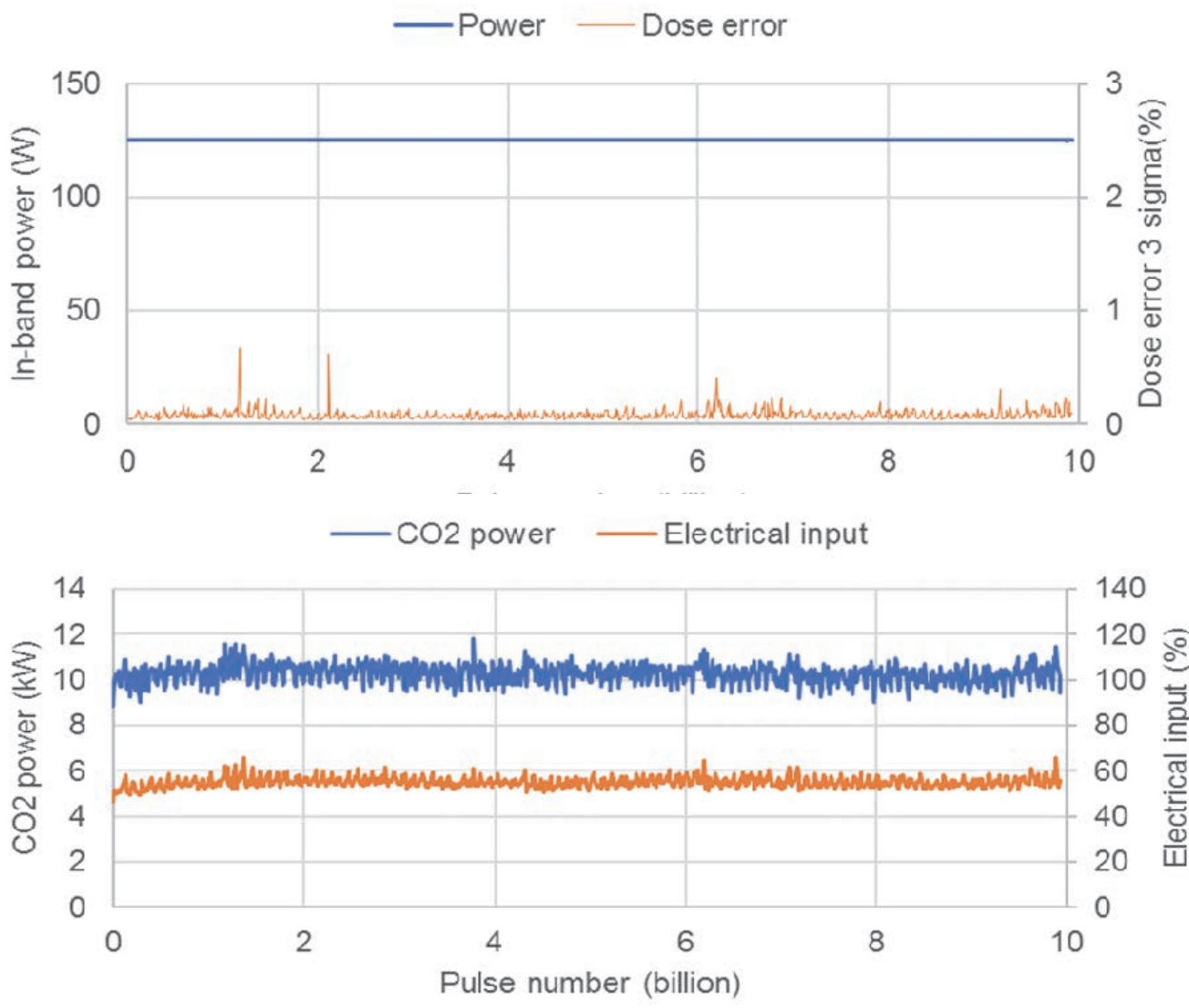

Fig. 9. EUV dose data. 
point, the other point is correspond to intermediate focus point. The surface is coated with 50 pare of $\mathrm{Mo} / \mathrm{Si}$ layers. The surface is coated by capping layer.

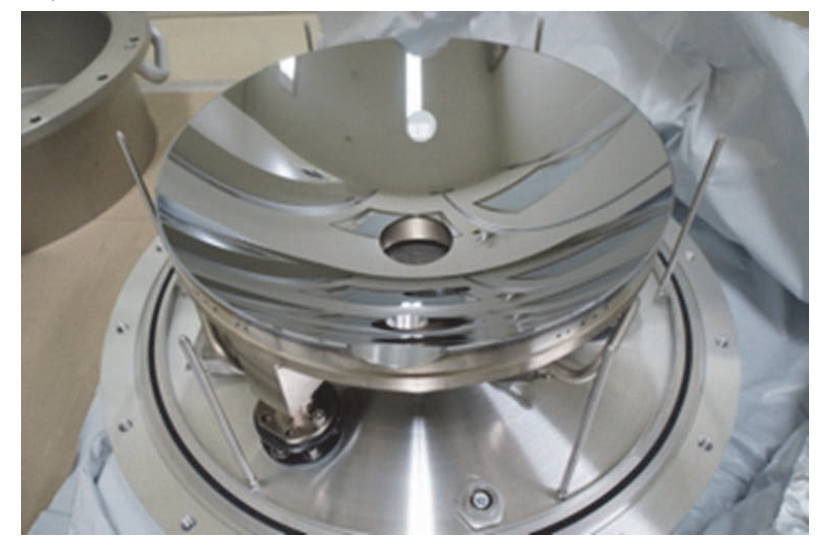

Fig. 10. Picture of actual collector mirror.

After EUV plasma is created, EUV light is collected by multilayer mirror. Figure 11 shows the schematic of this new filter. However EUV plasma emits not only EUV light, but also UV light, visible light and infrared light respectively. These light components are called "Out of band light" (Fig. 12). Reflected IR light from the multilayer makes interference pattern at focal plane (patented). Only IR light is absorbed by aperture stop.

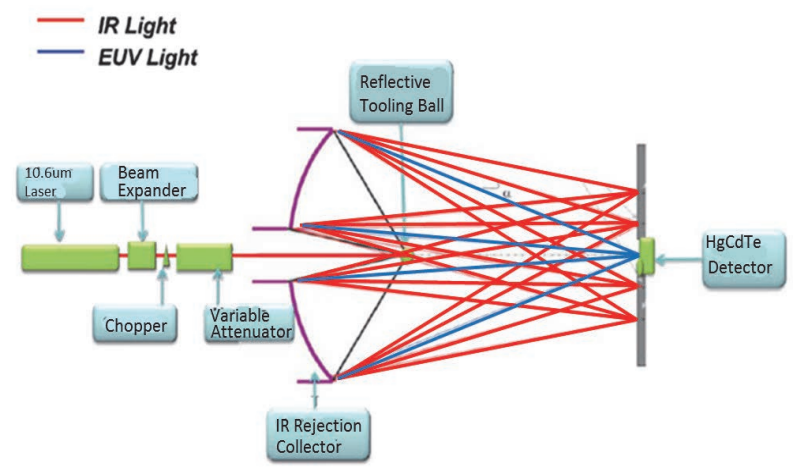

Fig. 11. Schematic of new type filter.

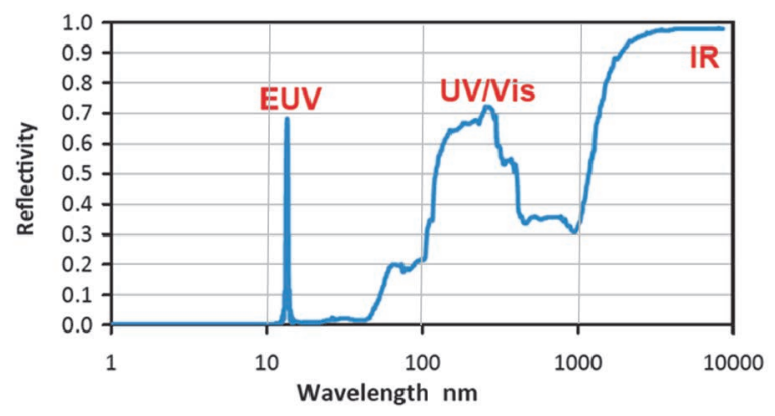

Fig. 12. Out of band spectrum.
Also capping layer has important role to avoid deposition of thin. Figure 13 shows significant deference between capping layer materials (A, B, $\mathrm{C})$. The "material A" shows blistering of the capping layer. The "material B" shows no blistering, but thick deposition of thin. The "material C" shows very good performance of Tin deposition. Therefore we chose "material C" for capping layer. Figure 13 shows the change on thickness of multilayer and capping layer after usage. Thickness of capping layer is reduced after usage because of sputtering of fast Sn ion. Also 1st layer of Si increased with oxidization of Si.

Recently we have demonstrated, EUV power recorded at $125 \mathrm{~W}$ ( $125 \mathrm{~W}$ in average, $100 \%$ duty), with $4 \%$ conversion efficiency more than 10 billion pulses operation. The magnetic mitigation has demonstrated promising mirror degradation rate $(=$ $-0.6 \% / \mathrm{Gp}$ ). Figure 15 shows the degradation of reflectance of actual corrector mirror with "material C" capping layer. Blue and red color lines show degradation of corrector mirror with lower power and before improvement of gas flow on the surface of mirror and capping layer materials. This data shows very low degradation rate is realized at actual EUV source operation.

\section{Redefinition of EUV power target}

4.1. Recent progress of EUV power in the market

Since 2012 the speed of power improvement enhanced, because of innovation of light source technologies. One revolution is pre-pulse technology, the other revolution is progress of $\mathrm{CO}_{2}$ laser power. ASML reported their NEX3350 have realized $125 \mathrm{WPH}$ with $250 \mathrm{~W}$ EUV power in 2018. This means our $250 \mathrm{~W}$ power target is already meaning less from the point of business.

Therefore we decided to redefine our power target from $250 \mathrm{~W}$ to $330 \mathrm{~W}$. New target is described on Table 2. We have increased the power of driver laser $(10 \mathrm{~kW} \rightarrow 18 \mathrm{~kW})$, conversion efficiency $(4 \%$ $\rightarrow 6 \%)$ and lifetime of collector mirror $(0.6 \% / \mathrm{Bpls} \rightarrow 0.05 \% / \mathrm{Bpls})$.

\subsection{Improvement of conversion efficiency}

Since 2012 we have used 1 micron wavelength pico-second pre-pulse as pre-pulse laser (section 2-2) for higher conversion efficiency operation. In 2015 we started the thin plasma measurement (Shadowgraph imaging and Thomson scattering) cooperate with Tomita et al [23]. Our experiment shows relationship between distribution of thin atom, plasma density and plasma temperature (Fig. 


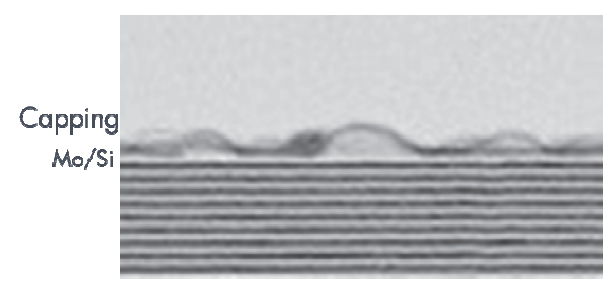

A

124W, 7.3Bpls

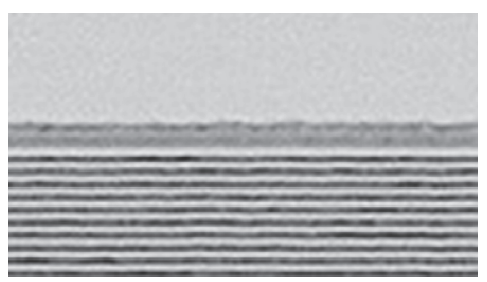

B

$124 \mathrm{~W}, 6.1 \mathrm{Bpls}$

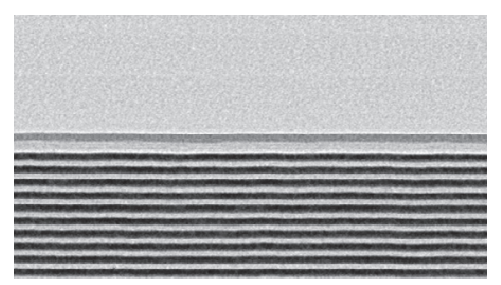

c

Fig. 13. Capping layer comparison (material A, B, C).
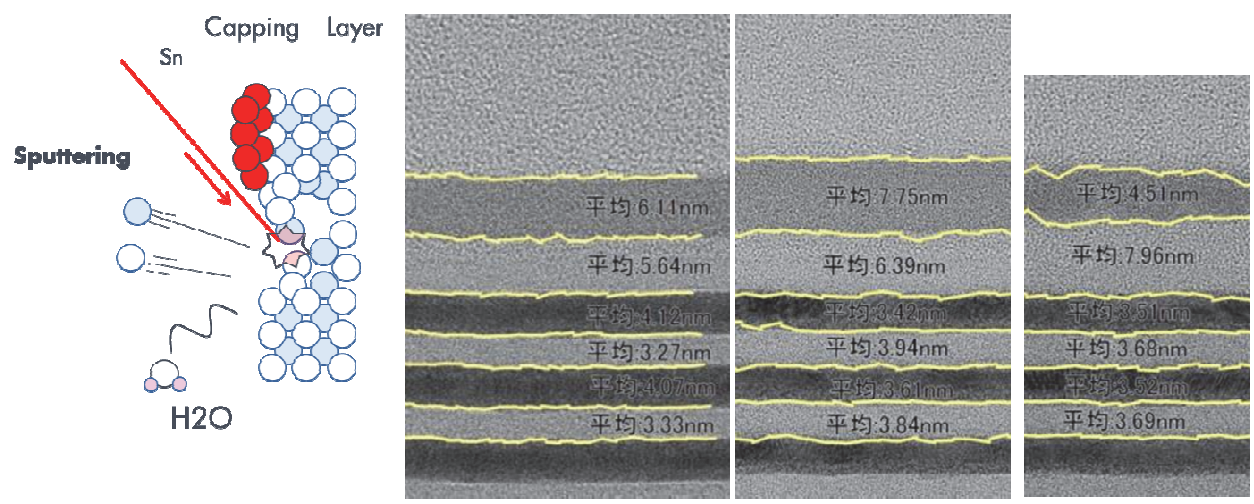

Capping Layer

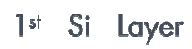

2nd Mo Layer

3rd Si Layer

Fig. 14. Thickness change of multilayer and capping layer after usage.

\section{Lifetime status}

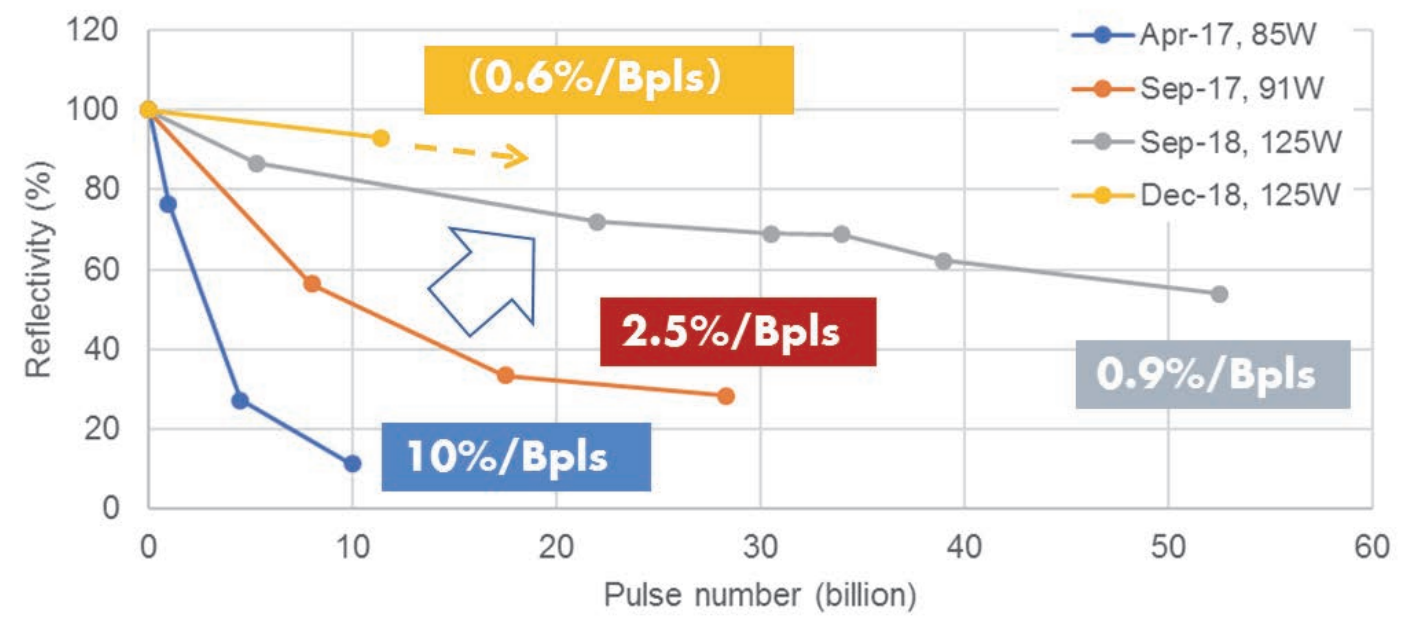

Fig. 15. Degradation of reflectance of actual corrector mirror.

Table 2. Redefined target of EUV source, parameters and key technologies.

\begin{tabular}{|c|c|c|c|}
\hline & & & \\
\hline Target & Q4 2018 & Under testing & Q4 2019 \\
\hline Average Power & $125 \mathrm{~W}$ & 250W & $\geqq 330 \mathrm{~W}$ \\
\hline Repetition rate & $100 \mathrm{kHz}$ & $100 \mathrm{kHz}$ & $100 \mathrm{kHz}$ \\
\hline $\begin{array}{l}\mathrm{CO} 2 \text { power (energy) at plasma } \\
\text { operation with dose ctrl./maximum }\end{array}$ & $\begin{array}{l}10 \mathrm{~kW} / 16 \mathrm{~kW} \\
(100 \mathrm{~mJ} / 160 \mathrm{~mJ})\end{array}$ & $\begin{array}{c}18 \mathrm{~kW} / 23 \mathrm{~kW} \\
(180 \mathrm{~mJ} / 230 \mathrm{~mJ})\end{array}$ & $\begin{array}{l}18 \mathrm{~kW} / 23 \mathrm{~kW} \\
(180 \mathrm{~mJ} / 230 \mathrm{~mJ})\end{array}$ \\
\hline CE & $4.0 \%$ & $4.5 \%$ & $5.5 \sim 6 \%$ \\
\hline Technology for high power & & & \\
\hline (1) Beam uniformity at plasma for $C E>6 \%$ & & & $\checkmark$ \\
\hline (2) Optimization of plasma parameters for CE $>6 \%$ & & $\checkmark$ & $\checkmark$ \\
\hline (3) Upgrade of CO2 Laser Power & & $\checkmark$ & $\checkmark$ \\
\hline (4) Lifetime Extension of Collector Mirror $-0.05 \% / \mathrm{B}$ pls & & & $\checkmark$ \\
\hline
\end{tabular}




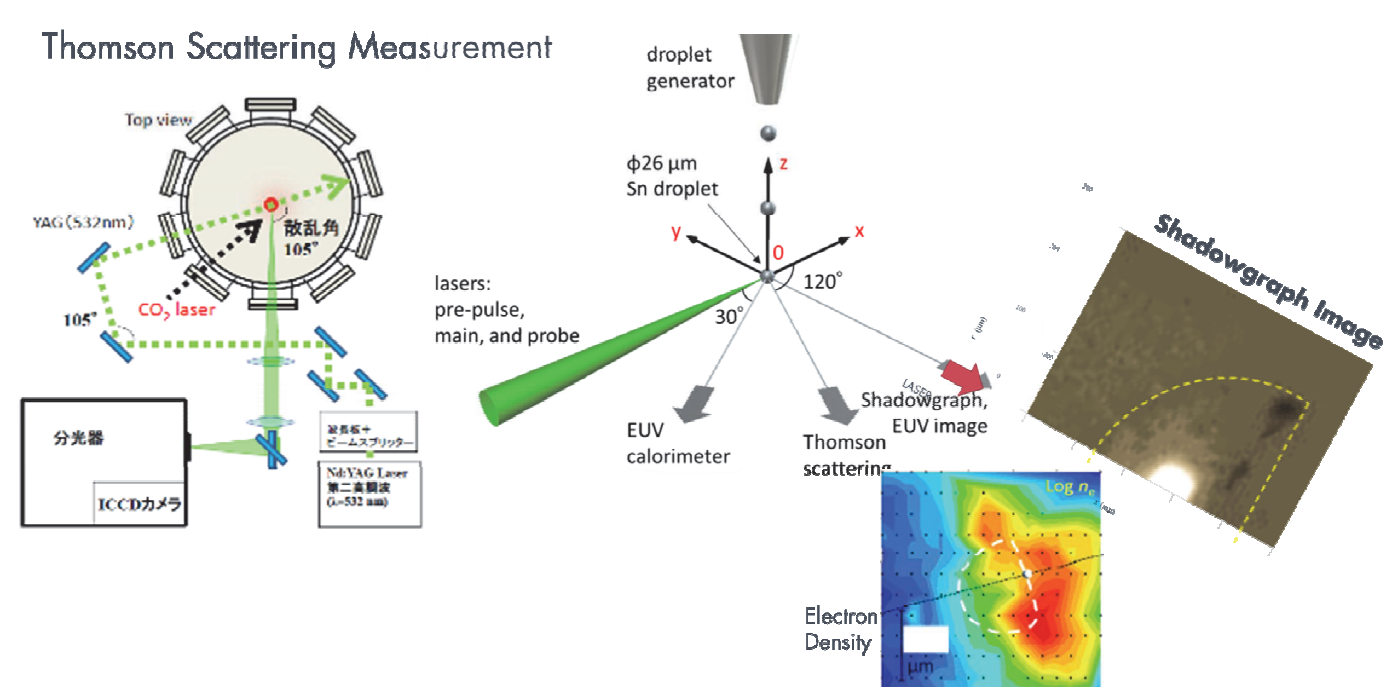

Fig. 16. Tomson scattering measurement system.

16).

Tomson scattering measurement shows, high temperature region and high density region is not same region. We think we still have a room for optimizations (Fig. 17).
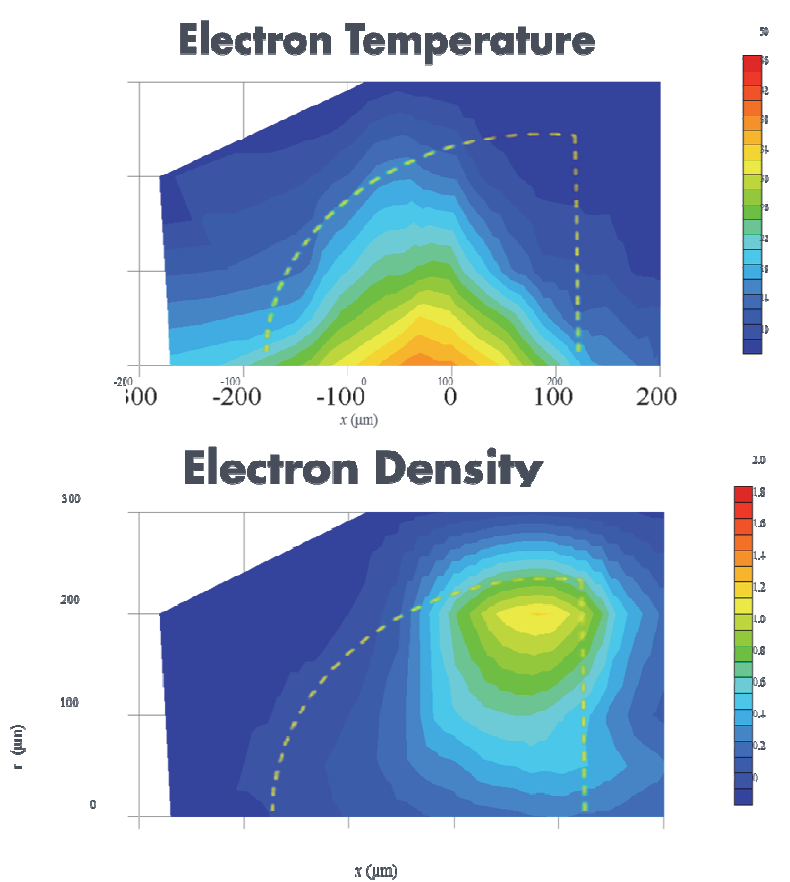

Fig. 17. Temperature and density distribution of electron.

\subsection{Improvement of driver laser power}

One of the important factor of higher driver laser power. We have improved the maximum power of driver laser system by improvement of optical design between pre-amplifier and Main 3 amplifiers. Figure 18 shows the input power and output power of driver $\mathrm{CO}_{2}$ laser system. Old maximum power was around $20 \mathrm{~kW} \mathrm{CO}$ laser output power. On the other hand after the improvement $27 \mathrm{~kW} \quad \mathrm{CO}_{2}$ laser power was achieved at $400 \mathrm{~kW}$ input power of $\mathrm{CO}_{2}$ laser system.

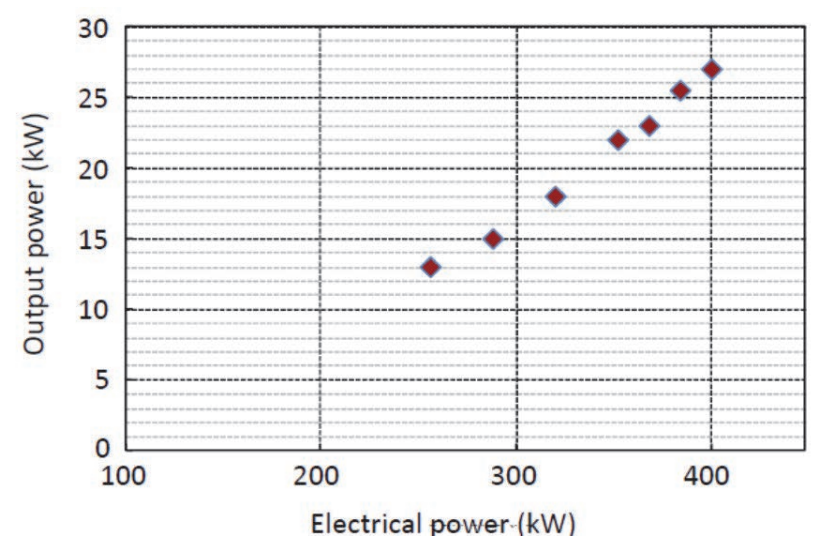

Fig. 18. Improvement of driver $\mathrm{CO}_{2}$ laser power.

\subsection{Improvement of capping layer material} We also have been screening the capping layer material corporate with "New SUBARU" in Hyogo University [24]. We have irradiated several capping layer sample materials and observed the degradation rate of reflectivity at $13.5 \mathrm{~nm}$. Figure 19 shows layer $\mathrm{C}$ is best of three materials.

\section{Conclusion}

We have developed Pilot \#1 system for HVM EUV lithography. Pilot\#1 is up running and it demonstrates HVM capability. We achieved following performances at present;

1) High conversion efficiency $4.5 \%$ is realized with Pre-pulse technology.

2) High speed $(>90 \mathrm{~m} / \mathrm{s}) \&$ small (20 micron) 

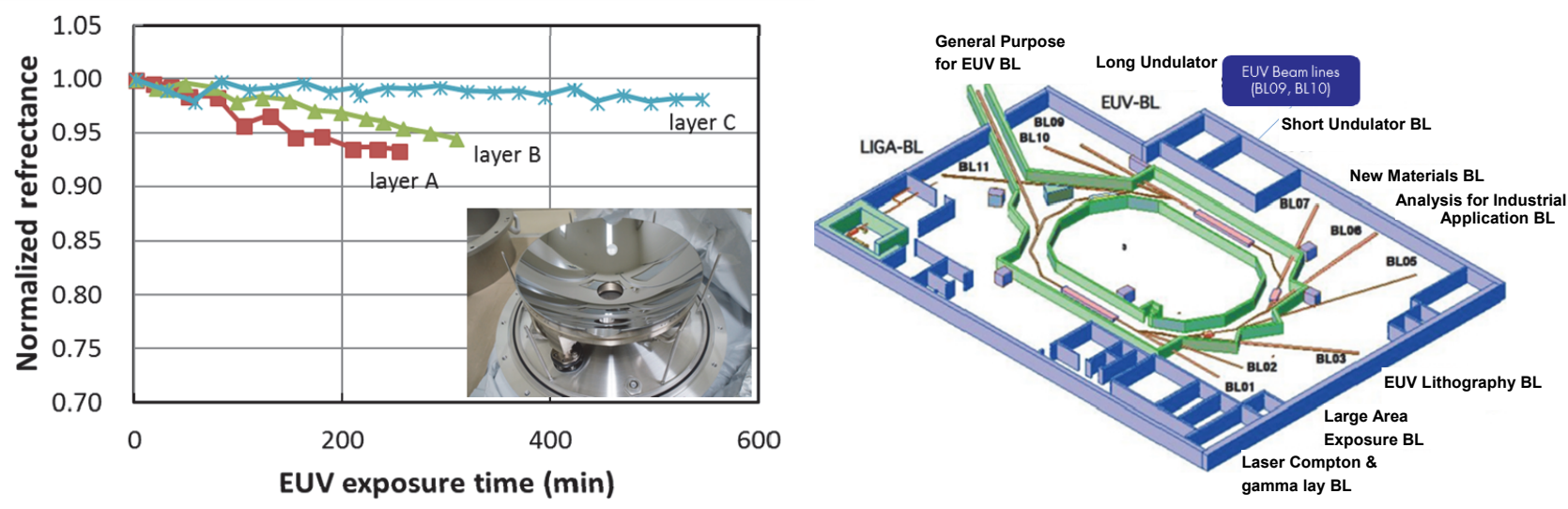

Fig. 19. Reflectivity measurement of actual corrector mirror.

droplet is realized.

3) High power $\mathrm{CO}_{2}$ laser power level is $20 \mathrm{~kW}$.

4) Output power 250 W in-burst power@ @50\% duty (125 W average) several min.

5) Pilot\#1 system achieved potential of $89 \%$ availability ( 2 weeks) at $125 \mathrm{~W}$ average power.

6) $-0.6 \% / \mathrm{Gpls}$ with $125 \mathrm{~W}$ average was demonstrated during 30Mpls with mirror test.

Recently we redefined target power to $\geqq 330 \mathrm{~W}$ to fit the demand of market;

1) Gigaphoton redefined power target to $\geqq 330 \mathrm{~W}$ ave. with $-0.05 \% / \mathrm{Gpls},>90 \%$ availability.

2) $\mathrm{CO}_{2}$ laser power upgrade $>27 \mathrm{~kW}$ is successfully demonstrated.

3) $\mathrm{CE}$ enhancement condition $>6 \%$ is clarified through small experimental device by Tomson scattering measurement.

Our new target is system demonstration of $\geqq$ $330 \mathrm{~W}$ operation will be by Q4 2019.

\section{Acknowledgement}

This work was partly supported by the New Energy and Industrial Technology Development Organization (NEDO), Japan. We acknowledge their continuous support.

We acknowledge to following researchers and organizations; Plasma simulation is supported by Dr. Jun Sunahara in Osaka University. Plasma diagnostics is supported by Dr. Kentaro Tomita, Prof. Kiichiro Uchino and others in Kyushu University. Laser engineering is supported by Dr. Akira Endo in HiLase Project (Prague). Also collector mirror suppliers - especially RIT. Also $\mathrm{CO}_{2}$ laser amplifier development is supported by Mitsubishi electric $\mathrm{CO}_{2}$ laser amp. develop. team: Dr. Yoichi Tanino, Dr. Junichi Nishimae, Dr. Shuichi Fujikawa and others.

\section{References}

1. N. Harned, M. Goethals, R. Groeneveld, P. Kuerz, M. Lowisch, H. Meijer, H. Meiling, K. Ronse, J. Ryan, M. Tittnich, H.-J. Voorma, J. Zimmerman, U. Mickan, and S. Lok, Proc. SPIE, 6517 (2007) 651706.

2. T. Miura, K. Murakami, K. Suzuki, Y. Kohama, K. Morita, K. Hada, Y. Ohkubo, and H. Kawai, Proc. SPIE, 6921 (2008) 69210M.

3. C. Wagner, N. Harned, P. Kuerz, M. Lowisch, H. Meiling, D. Ockwell, R. Peeters, K. van Ingen-Schenau, E. van Setten, J. Stoeldraijer, and B. Thuering, Proc. SPIE, 7636 (2010) $76361 \mathrm{H}$.

4. C. Wagner, J. Bacelar, N. Harned, E. Loopstra, S. Hendriks, I. de Jong, P. Kuerz, L. Levasier, M. van de Kerkhof, M. Lowisch, H. Meiling, D. Ockwell, R. Peeters, E. van Setten, J. Stoeldraijer, S. Young, J. Zimmerman, and R. Kool, Proc. SPIE, 7969 (2011) 79691F.

5. R. Peeters, S. Lok, E. van Alphen, N. Harned, P. Kuerz, M. Lowisch, H. Meijer, D. Ockwell, E. van Setten, G. Schiffelers, J.-W. van der Horst, J. Stoeldraijer, R. Kazinczi, R. Droste, H. Meiling, and R. Kool, Proc. SPIE, 8679 (2013) 86791F.

6. J. J. H. Chen, "Progress on enabling EUV lithography for high volume manufacturing" 2015 EUVL Symposium, October 2015, Maastricht, Netherlands.

7. M. Phillips, "EUVL readiness for 7nm", 2015 EUVL Symposium, October 2015, Maastricht, Netherlands.

8. H. Mizoguchi, H. Nakarai, T. Abe, T. Ohta, K. Nowak, Y. Kawasuji, H. Tanaka, Y. Watanabe, T. Hori, T. Kodama, Y. Shiraishi, T. Yanagida, T. Yamada, T. Yamazaki, S. Okazaki, and T. Saitou, Proc. SPIE, 9048 (2014) 90480D. 
9. Y. Tanino, J. Nishimae, T. Yamamoto, K. Funaoka, T. Tamida, S. Tsuda, S. Fujikawa, T. Ohta, and Y. Kawasuji, "A Driver CO2 Laser Using Transverse-flow CO2 Laser Amplifiers", EUV Symposium 2013, October 2013, Toyama, Japan.

10. H. Mizoguchi, H. Nakarai, T. Abe, K. M. Nowak, Y. Kawasuji, H. Tanaka, Y. Watanabe, T. Hori, T. Kodama, Y. Shiraishi, T. Yanagida, G. Soumagne, T. Yamada, T. Yamazaki, and T. Saitou, "High Power HVM LPP-EUV Source with Long Collector Mirror Lifetime", EUVL Workshop 2017, June 2017, Berkley, USA.

11. M. Purvis, I. Fomenkov, A. Schafgans, M. Vargas, S. Rich, Y. Tao, S. Rokitski, M. Mulder, E. Buurman, M. Kats, J. Stewart, A. LaForge, C. Rajyaguru, G. Vaschenko, A. Ershov, R. Rafac, M. Abraham, D. Brandt, and D. Brown, Proc. SPIE, 10583 (2018) 1058327.

12. Y. Ueno, H. Hoshino, T. Ariga, T. Miura, M. Nakano, H. Komori, G. Soumagne, A. Endo, H. Mizoguchi, A. Sumitani, and K. Toyoda, Proc. SPIE, 6517 (2007) 65173B.

13. H. Mizoguchi, T. Abe, Y. Watanabe, T. Ishihara, T. Ohta, T. Hori, T. Yanagida, H. Nagano, T. Yabu, S. Nagai, G. Soumagne, A. Kurosu, K. Nowak, T. Suganuma, M. Moriya, K. Kakizaki, A. Sumitani, H. Kameda, H. Nakarai, and J. Fujimoto, Proc. SPIE, 7969 (2011) 796908.

14. K. Nishihara, A. Sasaki, A. Sunahara, and T. Nishikawa, "Conversion efficiency of LPP source", EUV Sources for Lithography, Chap. 11, V. Bakshi, Ed., SPIE, Bellingham, 2005.

15. H. Tanaka, A. Matsumoto, K. Akinaga, A. Takahashi, and T. Okada, Appl. Phys. Lett., 87 (2005) 041503.

16. J. Fujimoto, T. Ohta, K. Nowak, T. Suganuma, H. Kameda, M. Moriya, T. Yokoduka, K. Fujitaka, A. Sumitani, and H. Mizoguchi, Proc. SPIE, 7969 (2011) 79692S.

17. Y. Tanino, "A proposal for an EUV light source using transverse flow $\mathrm{CO} 2$ lasers", International Symposium on Extreme
Ultraviolet Lithography 2012, October 2012, Brussel, Belgium, p. 1016.

18. K. M. Nowak, Y. Kawasuji, T. Ohta, T. Suganuma, T. Yokoduka, H. Nakarai, T. Yamazaki, T. Saito, H. Mizoguchi, Y. Tanino, and J. Nishimae, "EUV driver CO2 laser system using multi-line nano-second pulse high-stability master oscillator for Gigaphoton's EUV LPP system", EUV Symposium 2013, October 2013, Toyama, Japan.

19. H. Mizoguchi, H. Nakarai, T. Abe, T. Ohta, K. M. Nowak, Y. Kawasuji, H. Tanaka, Y. Watanabe, T. Hori, T. Kodama, Y. Shiraishi, T. Yanagida, G. Soumagne, T. Yamada, T. Yamazaki, S. Okazaki, and T. Saitou, "Update of one hundred watt HVM LPP-EUV source performance", 2015 EUVL Symposium, October 2015, Maastricht, Netherlands.

20. K. Yasui, N. Nakamura, J.-i. Nishimae, M. Naruse, K. Sugihara, and M. Matsubara, "Stable and scalable $\mathrm{CO} 2$ laser drivers for high-volume-manufacturing extreme ultraviolet lithography applications" 2016 EUVL symposium, October 2016, Hiroshima, Japan.

21. H. Mizoguchi, H. Nakarai, T. Abe, K. M. Nowak, Y. Kawasuji, H. Tanaka, Y. Watanabe, T. Hori, T. Kodama, Y. Shiraishi, T. Yanagida, T. Yamada, T. Yamazaki, S. Okazaki, and T. Saitou, Proc. SPIE, 9776 (2016) 97760J.

22. H. Mizoguchi, H. Nakarai, T. Abe, K. M. Nowak, Y. Kawasuji, H. Tanaka, Y. Watanabe, T. Hori, T. Kodama, Y. Shiraishi, T. Yanagida, T. Yamada, T. Yamazaki, S. Okazaki, and T. Saitou, Proc. SPIE, 10143 (2017) 101431J.

23. K. Tomita, Y. Sato, S. Tsukiyama, T. Eguchi, K. Uchino, K. Kouge, H. Tomuro, T. Yanagida, Y. Wada, M. Kunishima, G. Soumagne, T. Kodama, H. Mizoguchi, A. Sunahara, and K. Nishihara, Sci. Rep., (2017) 12328.

24. T. Harada and T. Watanabe, Proc. SPIE, 10809 (2018) 108091T. 